\title{
The current status and future needs of global bioaerosol research: a bibliometric analysis
}

\author{
E. Can-Güven ${ }^{1}[\mathbb{C}$
}

Received: 8 November 2020 / Revised: 18 July 2021 / Accepted: 20 September 2021 / Published online: 3 October 2021

(C) Islamic Azad University (IAU) 2021

\begin{abstract}
A bibliometric analysis was conducted to reveal the global status and highlight significant or promising areas of bioaerosol research based on the Web of Science database from 1989 to 2019. Yearly publications, main subject categories, journals, the performance of countries, and research hot topics were identified. The network of keywords and collaborations of countries was visualized and cross relationships were determined. Results showed that the annual output in the field increased during the related period. The USA, China, and Germany are the leading countries while the USA, Germany, and the UK are the most collaborative countries in bioaerosol research. "Journal of Aerosol Science" is the most productive journal and "Environmental Sciences \& Ecology" is the most popular research area. The research hot spots are health effects, sampling, particulate matter, and indoor air quality in the bioaerosol topic. The findings of this research could provide information to understand the development and trends as well as future needs of bioaerosol research.
\end{abstract}

Keywords Aerosol $\cdot$ Indoor air quality $\cdot$ Particulate matter $\cdot$ Research trend $\cdot$ Social network analysis

\section{Introduction}

Bioaerosols are airborne particles of biological origins including fungi, bacteria, viruses, pollen, and their metabolic fragments such as endotoxins, mycotoxins, and glucans (Cox and Wathes 1995). Bioaerosols are generated from outdoor activities, for instance, waste recycling, biosolid land application, composting, agriculture (Xu et al. 2011), as well as indoor human activities, namely sneezing, coughing, washing floors, toilet cleaning, walking, talking, etc. (Chen and Hildemann 2009; Mandal and Brandl 2011). Bioaerosols can functionally be classified into three main categories, namely, living organisms (e.g., bacteria, microalgae, fungi), components (e.g., fungal or bacterial spores, pollens, viruses), and fragments/exudates (e.g., mineral or salt particles) (Šantl-Temkiv et al. 2019). Bioaerosols exist in varying sizes ranging from $20 \mathrm{~nm}$ to $100 \mu \mathrm{m}$ (Pillai and

Editorial responsibility: Mohamed F. Yassin.

E. Can-Güven

ecguven@yildiz.edu.tr

1 Faculty of Civil Engineering, Department of Environmental Engineering, Yıldız Technical University, 34220 İstanbul, Turkey
Ricke 2002), and the inhalable fraction is of primary concern since it is plausible to reach the deeper parts of the respiratory system (Pope et al. 1995). Airborne particles are transported in the environment due to their light weights (Mandal and Brandl 2011). The transport and settling of the bioaerosols are dependent on their characteristics (e.g., size, density, shape) and meteorological factors (e.g., humidity, temperature) (Stetzenbach 2007).

Although the presence of biological agents in the atmosphere has been known for centuries (Morris et al. 2008), studies on bioaerosols have started to attract attention in recent years. The reason for this is mainly due to the realization that bioaerosol exposure resulted in a wide range of adverse health effects including contagious infectious diseases, respiratory diseases, allergies, and cancer (Douwes et al. 2003). Various studies revealed that in many cases exposure to airborne microorganisms leads to several health problems, namely, asthma and rhinitis (Beaumont 1988), hypersensitivity pneumonitis (Siersted and Gravesen 1993), and infections (Ren et al. 1999).

The past episodes of severe acute respiratory syndrome (SARS), Middle East respiratory syndrome (MERS), H1N1 infection, the potential danger of bird flu pandemic (Xu et al. 2011), and the bioterrorism incident in America in 2001 related to airborne Bacillus anthracis spores (Lee 
2011) have attracted worldwide attention on bioaerosols. Recently, airborne aerosols have become the main topic along with the pandemic of Novel Coronavirus (2019$\mathrm{nCoV}$ ) due to the airborne transmission of SARS-CoV-2 (Asadi et al. 2020).

Many review papers were published about bioaerosols including physical and chemical characterization of bioaerosols (Ariya et al. 2009), past, present, and future of bioaerosol science (Xu et al. 2011), health effects of bioaerosols, and exposure assessment (Douwes et al. 2003), observations and health effects of bioaerosols (Humbal et al. 2018), bioaerosol field measurements (Šantl-Temkiv et al. 2019), bioaerosols and health (Schlosser 2019), the effects of meteorological factors on bioaerosols (Jones and Harrison 2004). However, there is a lack of overall evaluation of the current situation and future needs of the bioaerosol research area.

Bibliometric analysis, firstly introduced by Pritchard (1969), provides a broad spectrum view of research trends in a specific field. It includes a series of quantitative analyses to review the evolution and development trend of a subject to reveal the current situation and identify the future needs of a particular topic. It is often used to assess what research needs to be undertaken and/or funded by the government to determine the regional research needs. It has been applied to various topics such as biogenic volatile organic compounds ( $\mathrm{Li}$ et al. 2017b), haze (Li et al. 2017a), $\mathrm{PM}_{2.5}$ (Zhao et al. 2016), aerosol (Xie et al. 2008), secondary organic aerosols ( $\mathrm{Li}$ et al. 2013), meteorology and atmospheric sciences (Zhang et al. 2012), sources of atmospheric pollution (Li et al. 2017c), lean and clean(er) production (Taddeo et al. 2019), carbon capture and storage (Li et al. 2019), floating treatment wetlands (Colares et al. 2020). However, to the best of the author's knowledge, a bibliometric analysis covering the bioaerosol topic does not exist.

This paper aimed to investigate the current knowledge in the bioaerosol research field through bibliometric analysis and social network analysis. Scientific publications about bioaerosols indexed in Web of Science Core Collection were investigated through bibliometric tools. The characteristics of outputs, the geographical distribution of publications, the performance of countries, distribution of journals, and research areas were evaluated. Research trends and hot topics in the field were determined via co-occurrence and network analysis of the author keywords and evolution of author keywords during the concerned period. This study presented the current global status of studies on the bioaerosol topic and filled the gap in the literature on this subject. This paper also highlighted significant research areas of the bioaerosol research field and made suggestions for future researches on bioaerosols.

\section{Material and methods}

The data used in this study were retrieved from the Web of Science (WoS) Core Collection, a widely used source for the broad analysis of scientific performance in all fields of science (Aghaei Chadegani et al. 2013). An advanced search was conducted in March 2020 using the search term TS = ("bioaerosol $*$ " OR "bio-aerosol*") to catch different usage of those keywords. The "topic" search field was chosen since it searches throughout the "title", "abstract", "keywords" and "keywords plus" of the publications. Thus, the most possible comprehensive search through WoS could be achieved and all publications were downloaded as 'Full Record'. The publications from 2020 were not included to avoid misevaluation due to the lack of the total yearly data. In total, 3354 publications were retrieved from the database and handled using a formerly developed and successfully applied data manipulation algorithm (Güven and Demirkale 2018). Only 2826 (84.3\% of all publications) articles were considered for further analysis since they would contain more comprehensive data. Other literature types (e.g., book reviews, meeting abstracts, letters) were excluded from the study. Since the first article was in 1989, the period was determined as 1989-2019 for further evaluation.

The impact factors (IF) (2018) and Q indexes of each journal were obtained from the journal citation reports (JCR) published by WoS for 2018. Collaboration type was determined by the addresses of authors, where the term "independent" was assigned if the researchers' addresses were from the same country, and "international collaboration" was designated to those articles that were co-authored by researchers from more than one country. Articles published by authors from England, Scotland, Northern Ireland, and Wales were concatenated under the UK heading.

All publications were assessed in the following aspects; characteristics of publication outputs, distribution in journals, subject areas, WoS categories, geographical distribution and performance of countries, and prevalence and social network analysis of the author keywords. To avoid misevaluation due to the nonstandard expression of keywords, the words with the same meaning such as bioaerosol and bioaerosols or misspelled words were combined. Also, the singular or plural forms of the words were merged. Co-occurrence analysis and social network analysis of the keywords and collaboration analysis of the countries were generated using Gephi, open-source software used for network visualization and manipulation (Bastian et al. 2009). Five intervals (1991-1999, 2000-2004, 2005-2009, 2010-2014, and 2015-2019) were used to evaluate the distribution and evolution of keywords. 


\section{Results and discussion}

\section{Characteristics of publication outputs}

The distribution of the annual publication outputs is shown in Fig. 1. During the 31 years of the target period, the number of articles in the field of bioaerosols increased from 2 in 1989 to 269 at the end of 2019. There was an obvious increasing trend in the number of total publications. This trend became evident in 1994 and despite some fluctuations; there was a steady increase in the total number of publications (Fig. 1). The rapid increase and development of bioaerosol research after 1994 can be related to the workshop of International Global Aerosol Program in 1993 (Morris et al. 2008) as well as getting attraction of this area with the publication of the first devoted special issue to bioaerosol research in 1994 (Xu et al. 2011). In the following periods, sharp increases have not been seen, however, some fluctuations were seen in the years 2004-2005 and 2010. The increase in the period of 2004-2005 can be related to the outbreaks of SARS (2003), bird flu (2004-2005), or bioterrorism events like anthrax in 2001 (Xu et al. 2011). On the other hand, the H1N1 outbreak that occurred in 2009 had drawn attention to bioaerosols and this might affect the increase in the number of publications after 2010. The number of publications on bioaerosols is still growing and in recent years bioaerosol research has attracted more attention and this topic has become a hot research field.

\section{Geographical distribution of publications and performance of countries}

The global distribution of studies on bioaerosols and productivity of countries are shown in Fig. 2 and Table 1. The USA was the leading country with 904 (32.0\%) publications and followed by China (278; 9.84\%), Germany (242; $8.56 \%$ ), Poland (204; 7.22\%), and South Korea (176; 6.23\%). The yearly fluctuation of the number of articles by the most productive five countries is given in Fig. 3. The bioaerosol studies in the USA started to increase in 1994 and exponentially increased over time. Moreover, China demonstrated a great interest in bioaerosol research and ranked in the top in 2019 with 64 articles while there were 2 papers from this country in 2001. The publication counts of the other three most productive countries stayed at a certain level and slightly increased after 2006. Five of the most productive ten countries (the USA, Germany, the UK, Canada, and France) are from the list of seven major industrialized countries (G7 countries). The high level of science and the development of technology in these countries (Yang et al. 2012) as well as the early pollution occurring in industrialized countries led to studies in the field of bioaerosols. 49 out of 71 countries over the period investigated had no publications before 2000 and 21 countries have their first publication on bioaerosols after 2010. It can be inferred that bioaerosol research recently started in many countries and became a global concern.

Among 2826 articles from 71 countries in the investigated period, only 518 (18.3\%) publications involve international collaborations. The USA and China ranked in the first
Fig. 1 Annual publication outputs

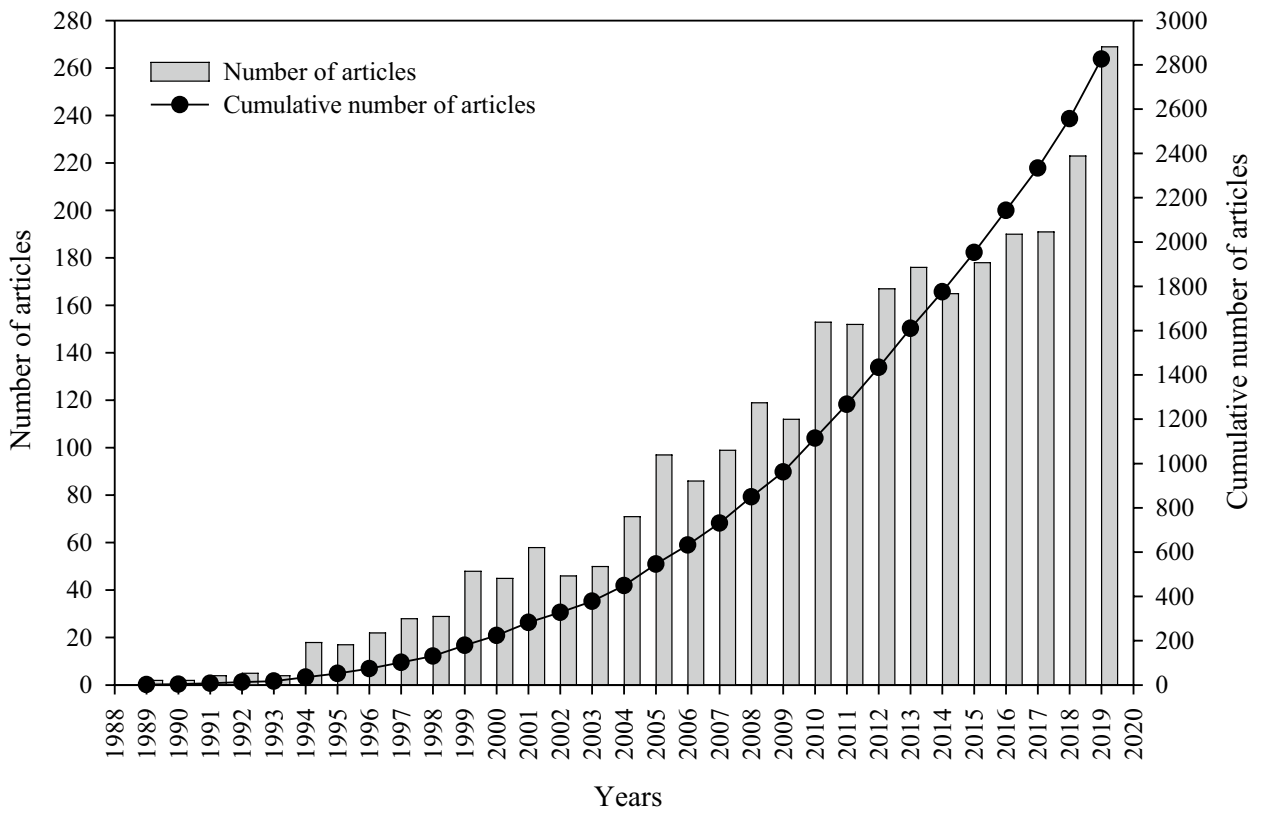




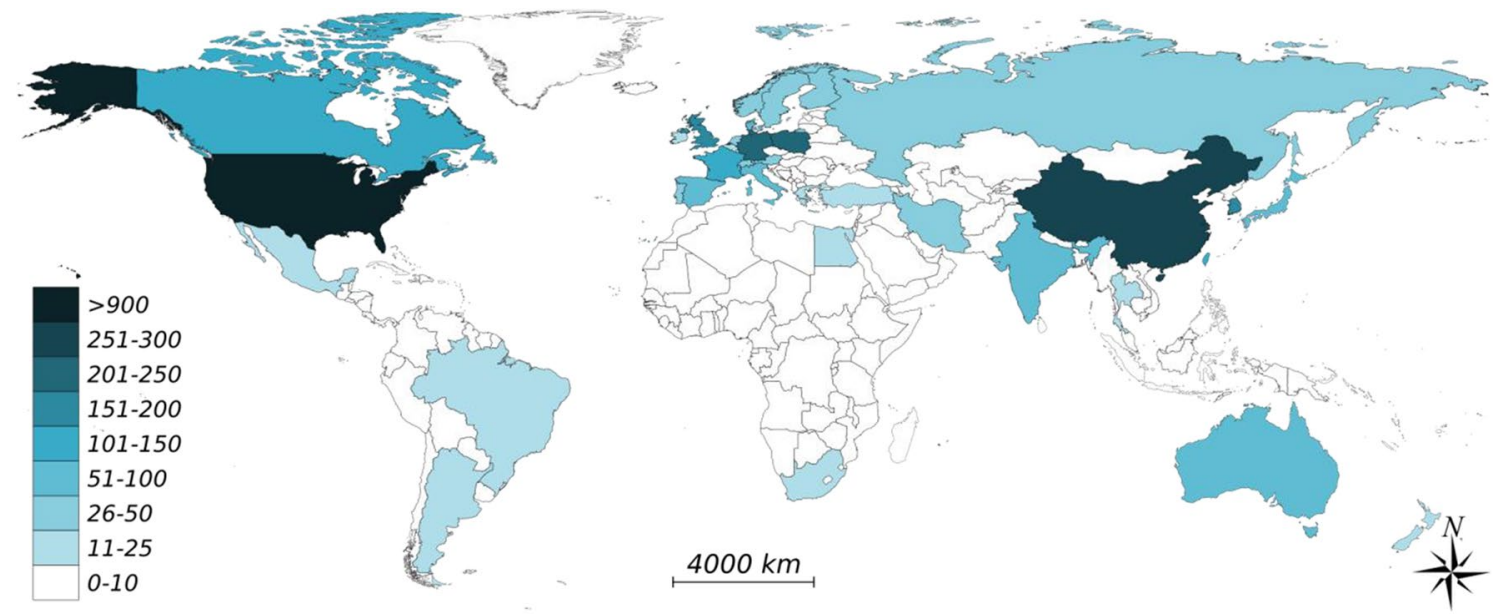

Fig. 2 Global geographical distribution of bioaerosol publications

Table 1 The ten most productive countries publishing articles on bioaerosols 1989-2019

\begin{tabular}{|c|c|c|c|c|c|c|c|c|c|}
\hline \multirow[t]{2}{*}{ Country } & \multicolumn{2}{|l|}{$\mathrm{TP}$} & \multicolumn{2}{|l|}{ SP } & \multicolumn{2}{|l|}{$\mathrm{CP}$} & \multicolumn{2}{|l|}{$\mathrm{RP}$} & \multirow[t]{2}{*}{ C, $\%$} \\
\hline & \# & $\mathrm{R}(\%)$ & \# & $\mathrm{R}(\%)$ & \# & $\mathrm{R}(\%)$ & \# & $\mathrm{R}(\%)$ & \\
\hline USA & 904 & $1(32.0)$ & 657 & $1(23.2)$ & 247 & $1(8.74)$ & 96 & $1(3.40)$ & 27.3 \\
\hline China & 278 & $2(9.84)$ & 202 & $2(7.15)$ & 76 & $2(2.69)$ & 40 & $2(1.42)$ & 27.3 \\
\hline Germany & 242 & $3(8.56)$ & 172 & $4(6.09)$ & 70 & $4(2.48)$ & 25 & $6(0.885)$ & 28.9 \\
\hline Poland & 204 & $4(7.22)$ & 182 & $3(6.44)$ & 22 & $13(0.778)$ & 14 & $10(0.495)$ & 10.8 \\
\hline South Korea & 176 & $5(6.23)$ & 131 & $5(4.64)$ & 45 & $5(1.59)$ & 31 & $4(1.10)$ & 25.6 \\
\hline UK & 171 & $6(6.05)$ & 96 & $7(3.40)$ & 75 & $3(2.65)$ & 28 & $5(0.991)$ & 43.9 \\
\hline Canada & 135 & 7 (4.78) & 95 & $8(3.36)$ & 40 & $7(1.42)$ & 15 & $9(0.531)$ & 29.6 \\
\hline Taiwan & 133 & $8(4.71)$ & 115 & $6(4.07)$ & 18 & $17(0.637)$ & 11 & 13 (0.389) & 13.5 \\
\hline France & 131 & $9(4.64)$ & 89 & $9(3.15)$ & 42 & $6(1.49)$ & 12 & $12(0.425)$ & 32.1 \\
\hline Australia & 78 & $10(2.76)$ & 33 & 15 (1.17) & 45 & 5 (1.59) & 32 & $3(1.13)$ & 57.7 \\
\hline
\end{tabular}

$T P$ total number of articles, $S P$ independent articles of the country, $C P$ internationally collaborative articles, $R P$ articles with the corresponding author, $R$ Rank, $C$ the percentage of internationally collaborative articles in total articles for each country two places in SP, CP, and RP lists (Table 1). The collaboration percentages of the most productive five countries were small compared to other countries. Moreover, the percentages of internationally collaborative articles in total articles (C, Table 1) for the UK, France, and Australia are higher than the first five countries indicating that these countries are more eager to collaborate.

The co-occurrence network of countries to evaluate international collaborations was generated using Gephi software (Fig. 4). According to this classification, all countries are divided into 5 clusters indicating that the countries in the same cluster have closer collaboration with each other. The USA is the most collaborative country and is the center of the biggest cluster (Cluster I, Fig. 4) which includes 29 countries globally. In addition to the USA, the first cluster includes Asia-Pacific countries, e.g., China, South Korea, Japan, Canada, New Zealand. Cluster I shows that many countries worldwide conducted collaborative studies about bioaerosols indicating that air-related issues are transboundary. Germany and the UK are the core of the second cluster which consists of 22 countries, most of which are EU countries such as France, Italy, Austria, and Portugal. Denmark is the core of the third cluster which consists of 8 countries some of which are from the Baltic region (e.g., Norway, Sweden). These two clusters (Cluster II and Cluster III) show that sharing the same geography, developmental level, similar pollution issues, and climatic conditions is likely to result in collaborative studies on a specific topic. These three clusters account for the majority (92.2\%) of the countries in the network.

The research hotspots differ between countries due to their developmental level, pollution issues, geographical and climatic conditions. The research hotspots of the most productive five countries were investigated through the top 7 keywords used in the publications by each country (Fig. 5). 
Fig. 3 The growth trends of the number of articles by the most productive five countries

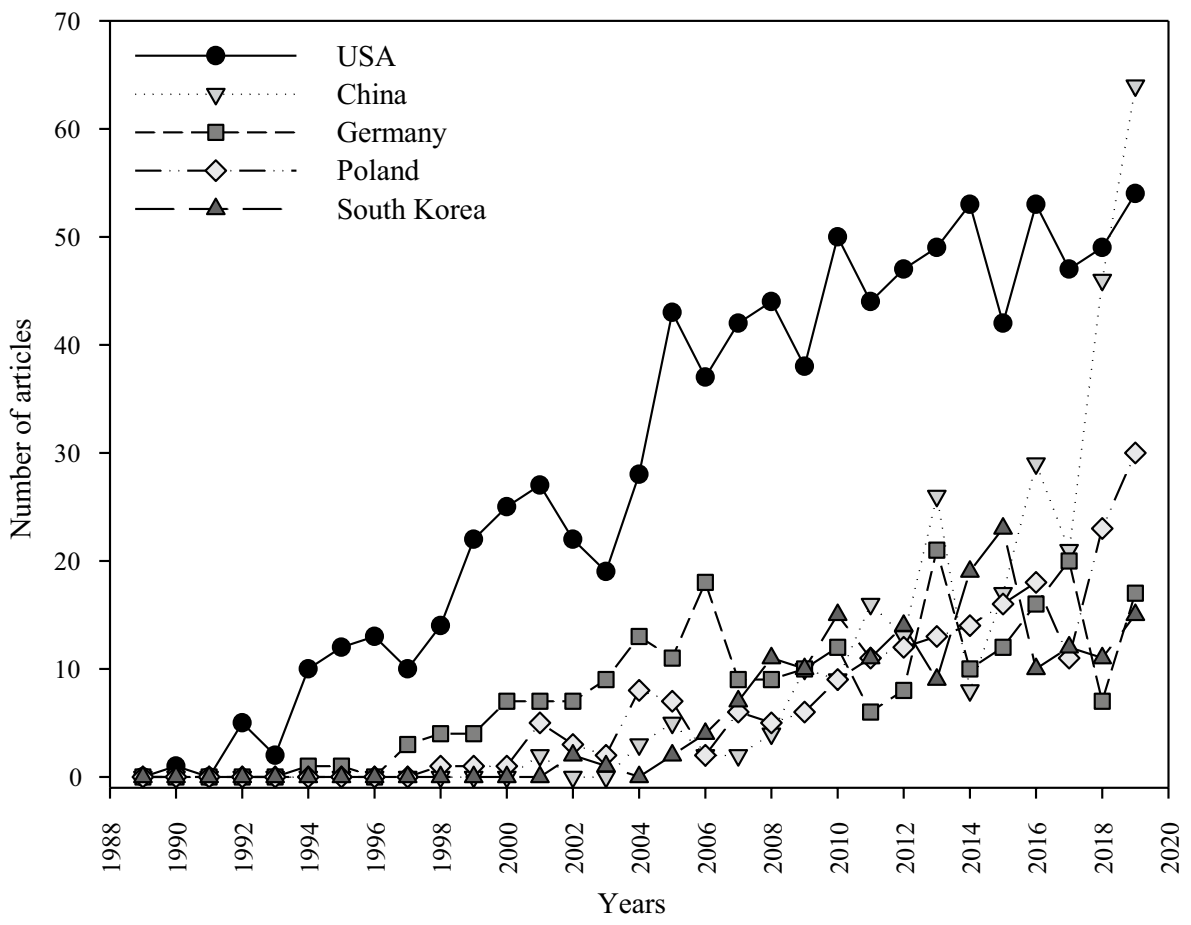

As shown in Fig. 5 bioaerosol constituents such as bacteria, fungi, endotoxins are common research topics for all five countries. Apart from this, size distribution and particulate matter are popular research topics in the USA, China, and Poland. Moreover, occupational exposure is a remarkable research topic in Germany and Poland. On the whole, bioaerosol-related research topics are generally common worldwide with some regional differences.

\section{Distribution of outputs in journals and research areas}

The 2826 articles were published in 627 different journals concerning bioaerosols during the related period. The most productive 20 journals are shown in Fig. 6 with the publication numbers, impact factors, and Q indexes of journals in 2018 according to JCR. Journal of Aerosol Science ranked the first with 145 (5.13\%) published articles followed by Aerosol Science and Technology (127; 4.49\%), Atmospheric Environment (116; 4.10\%), Science of The Total Environment (100;3.54\%), and Aerobiologia (95; 3.36\%), respectively. "Journal of Aerosol Science" and "Aerosol Science and Technology" publishes fundamental and experimental aspects of aerosols and "Atmospheric Environment" focuses on the atmospheric composition. The fourth one, "Science of The Total Environment" concentrates on the interaction of the total environment while the fifth one, "Aerobiologia" deals with allergens, pathogens, and aerobiology. The scopes of the most popular journals could give information on the preferences of the authors' research interests. Approximately half of the articles (43.8\%) were published in the first 20 journals, 13 of which have an impact factor above 2 and were in the first two Quartiles in WoS classification. In the case of journal productivity, the first publication years of the journals also have to be considered. For instance, the Journal of Aerosol Science began publishing in 1970 whereas the Journal of Environmental Monitoring's first volume was in 2012. As a natural result of the difference in the first years of publication, the total number of articles published in the journals varies.

The yearly distribution of 2826 articles in the top 5 research areas (total 89) and WoS subject categories (total 131) are shown in Figs. 7 and 8, respectively. There was an increase in all research areas and WoS categories throughout the period investigated along with the increase in the total number of publications. The most popular research area is "Environmental Sciences \& Ecology" while the most popular WoS category is "Environmental Sciences". The significant increase in both the research area "Environmental Sciences \& Ecology" and the WoS category "Environmental Sciences" during the period 1989-2019 indicates that bioaerosol research is a hot topic among environmental scientists. Moreover "Public, Environmental \& Occupational Health" and "Meteorology \& Atmospheric Sciences" categories are popular both among research areas and WoS categories indicating that these subjects have great attention by researchers. Furthermore, the top 5 research areas and WoS subject categories conformed well to the subject categories of the first 20 popular journals. 


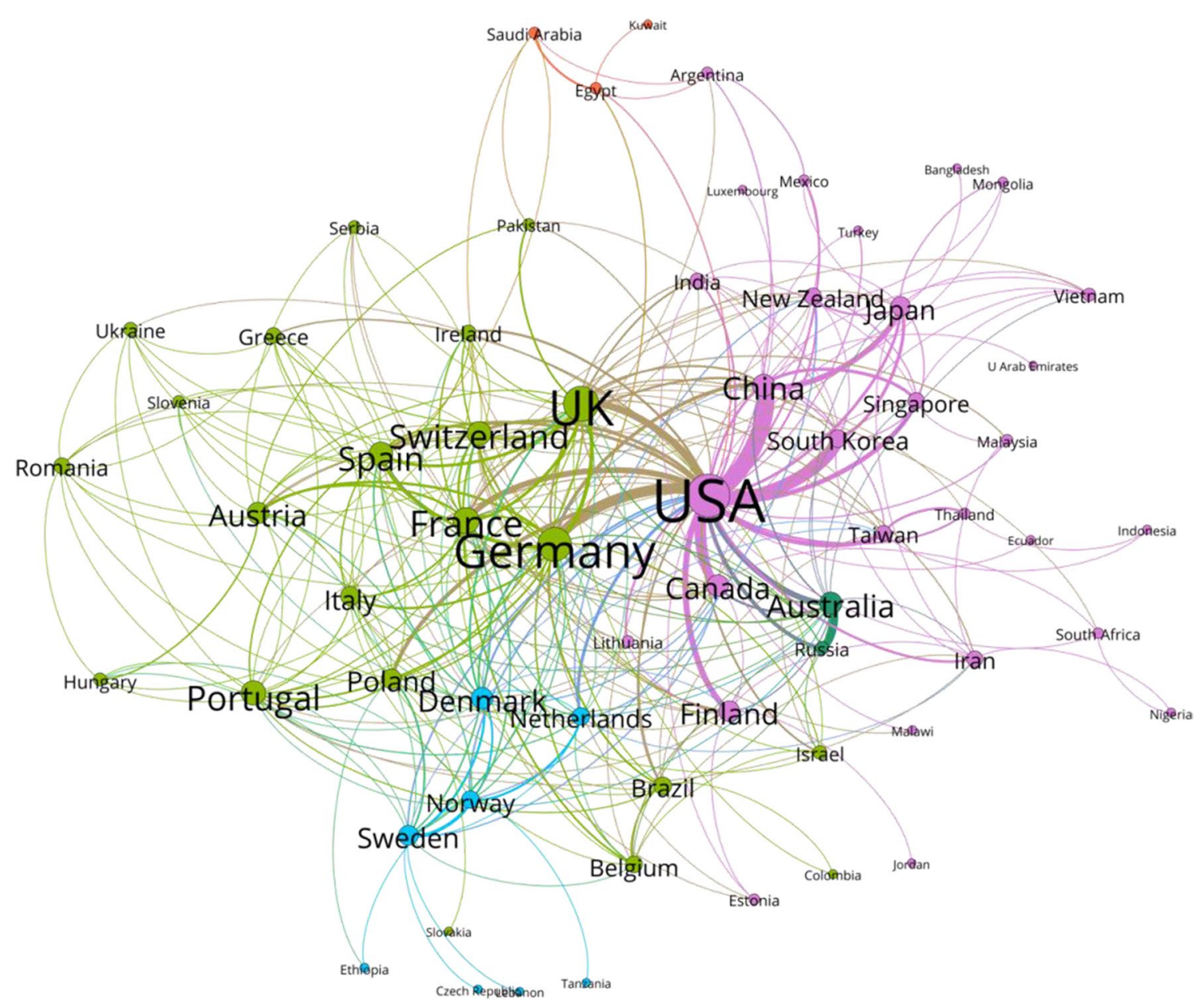

Fig. 4 The co-occurrence network and collaborations among countries (Note: nodes in Cluster I, Cluster II, Cluster III, Cluster IV, and Cluster V were colored in violet, light green, blue, orange, and dark green, respectively)

\section{Keywords analysis}

The analysis of author keywords could offer information about the research tendency of researchers (Garfield 1990). Keyword analysis revealed that there were 4241 different keywords listed by authors. Among them, 3040 $(71.7 \%)$ were used only once, $526(12.4 \%)$ words were used twice, and $227(5.35 \%)$ words were used three times. Only 448 (10.6\%) keywords were used more than three times indicating a lack of consistency in studies and a wide distribution in research topics (Xie et al. 2008; Fu et al. 2010; Can-Güven and Gedik 2016). Except "bioaerosol", the top 20 most frequently used author keywords are "Bacteria", "Fungi", "Endotoxin", "Indoor air quality", "Aerosol", "Occupational exposure", "Airborne bacteria", "Indoor air", "Fungal spore", "Size distribution", "Particulate matter", "Airborne fungi", "Microorganism", "Air quality", "Aerobiology", "Airborne microorganism", "Air pollution", "Exposure", "Organic dust" and "Dust". The distribution and evolution of author keywords during five time intervals were shown in Fig. 9. There were no keywords in the articles published before 1991, thus the first interval started in 1991. Several keywords referring to components and fragments of bioaerosols (e.g., bacteria, endotoxin, fungi) and research location (e.g., occupational exposure, indoor air quality) were present throughout the whole period and steadily increased over time, showing that the bioaerosol-related research was generally steady in the past 30 years. Moreover, the extinction of the keywords about sampling (e.g., sampling, collection efficiency) and health-related words such as asthma, allergy, and exposure assessment in the last ten years indicates that the research trends about these subjects are directed to other areas. Furthermore, "particulate matter" and related words such as "size distribution", "air quality", " $\mathrm{PM}_{2.5}$ " get promoted in the last ten years which might be identified as current bioaerosol research hotspots. This is not surprising since the last twenty years worldwide measurement programs were conducted to quantify bioaerosols as percentages of $\mathrm{PM}_{2.5}$ and $\mathrm{PM}_{10}$ (Hyde and Mahalov 2020). It can be concluded 

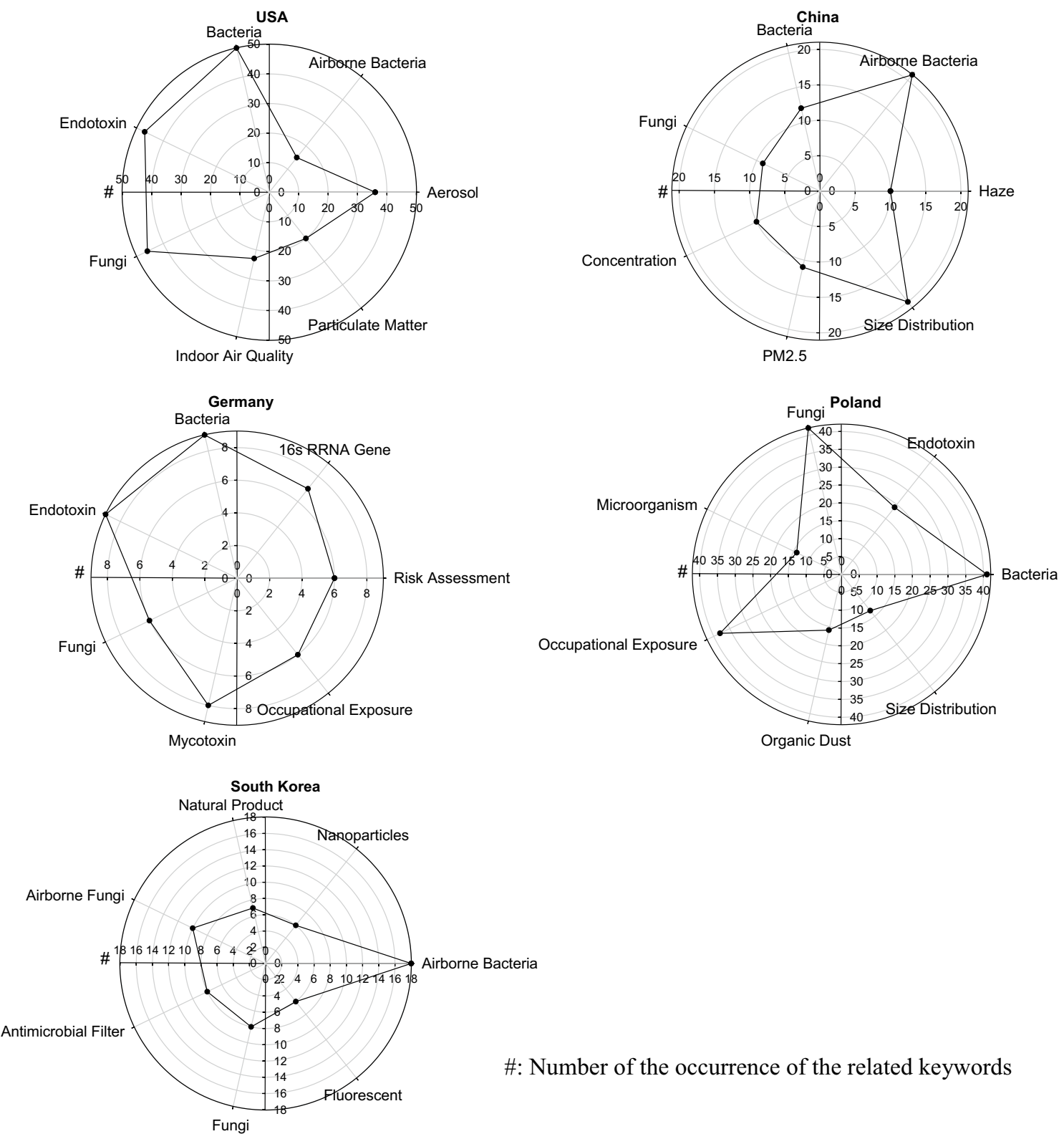

\#: Number of the occurrence of the related keywords

Fig. 5 The research trends of the most productive five countries

that more attention was paid to components of bioaerosols and the medical fields than to the physical sciences.

Co-words network analysis and clustering of author keywords were conducted using Gephi software (Fig. 10). The node size is related to the number of links connected to a node and is shown as the node degree $(D)$. The larger the node, the higher the link connected. Also, the thickness of the link shows the connection between the words. Five clusters were gathered from Gephi software by the community analysis. The proportion of the first cluster is $29.69 \%$ and the central node is "Endotoxin" $(D=116)$. "Endotoxin" has a strong connection with "Occupational Exposure" $(D=74)$ and "Microorganism" $(D=65)$. Endotoxins are components of gram-negative bacteria (Rolph et al. 2018) and occupational exposure to endotoxin-contaminated bioaerosols causes occupational hazards (Humbal et al. 2018). Moreover, the prevalence of keywords, i.e., "Occupational Health", "Allergy", "Asthma", "Exposure", "Respiratory Symptoms" in Cluster I indicates that the health effects of bioaerosols, especially occupational exposure, is a hot topic in the bioaerosol research field. Furthermore, some keywords in Cluster I such as "Composting" and "Wastewater Treatment Plant" are related to the emission sources of endotoxins (Rolph et al. 2018).

The keyword of "bacteria" $(D=156)$, which is a constituent of bioaerosols, is located in the center of Cluster II 
Fig. 6 Top 20 most productive journals in bioaerosol research during 1989-2019
Fig. 7 The growth trends of the top 5 research areas in bioaerosol research during 1989-2019
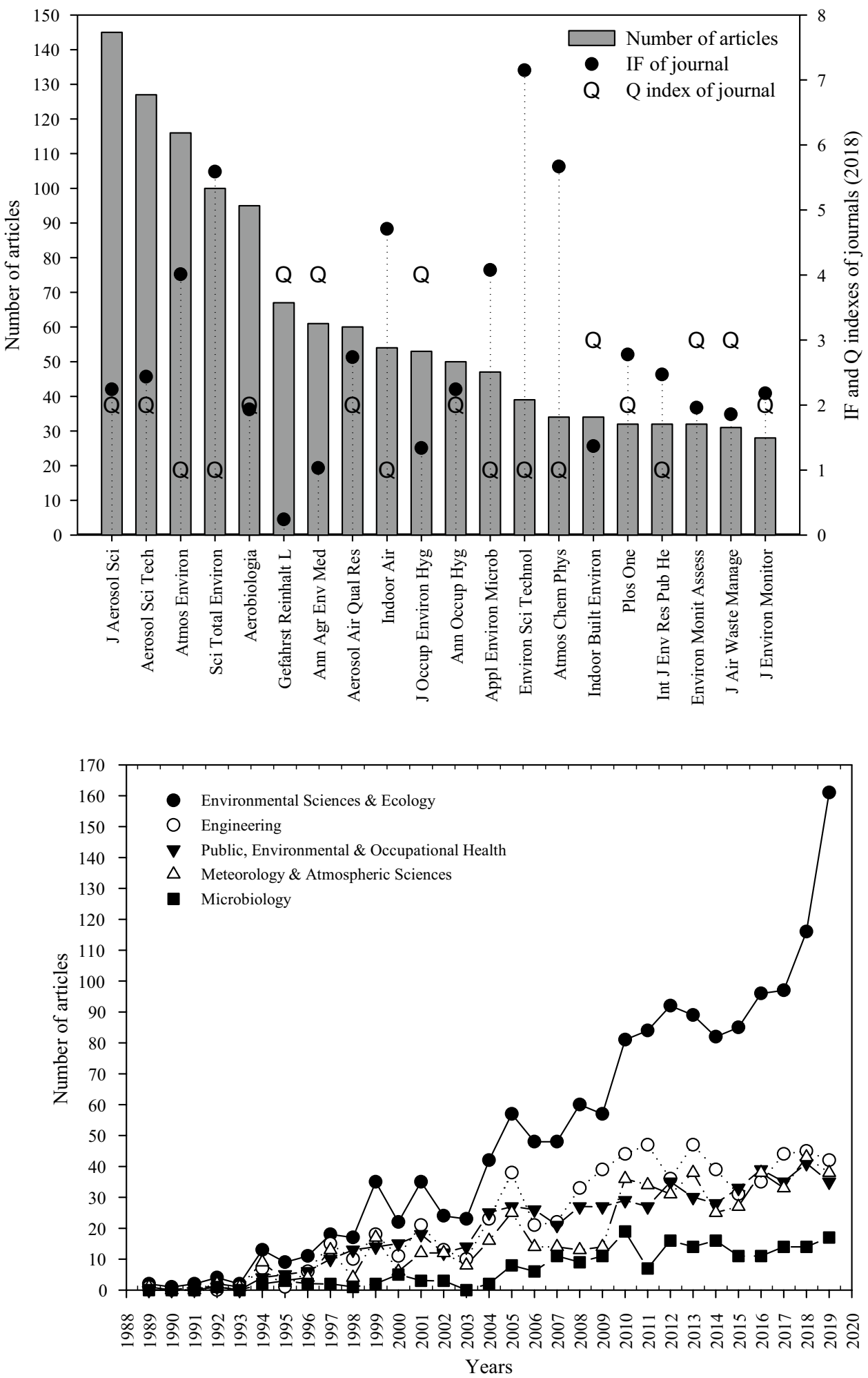

(the proportion is $24.69 \%$ ). It is strongly connecting with other bioaerosol components, namely "Fungus" $(D=149)$ and "Virus" $(D=30)$. Various keywords about sampling such as "Filtration", "Filter", "Sampling", "Collection Efficiency", "Impinger", and "Impactor" were in Cluster
II. Impaction, impingement, and filtration are commonly used bioaerosol sampling methods (Xu et al. 2011). The co-occurrence of these keywords with bioaerosol components shows that bioaerosol sampling is an important research topic. 
Fig. 8 The growth trends of the top 5 Web of Science categories in bioaerosol research during 1989-2019

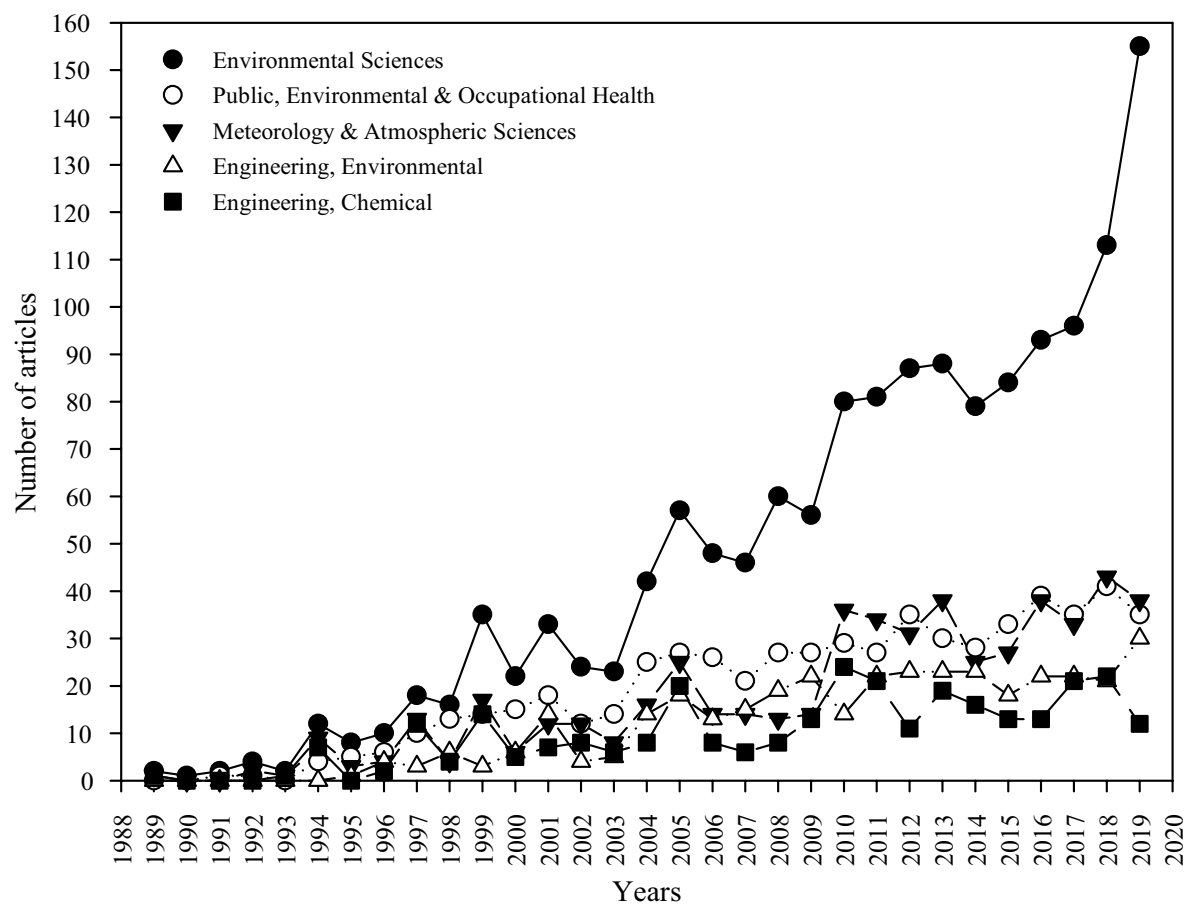

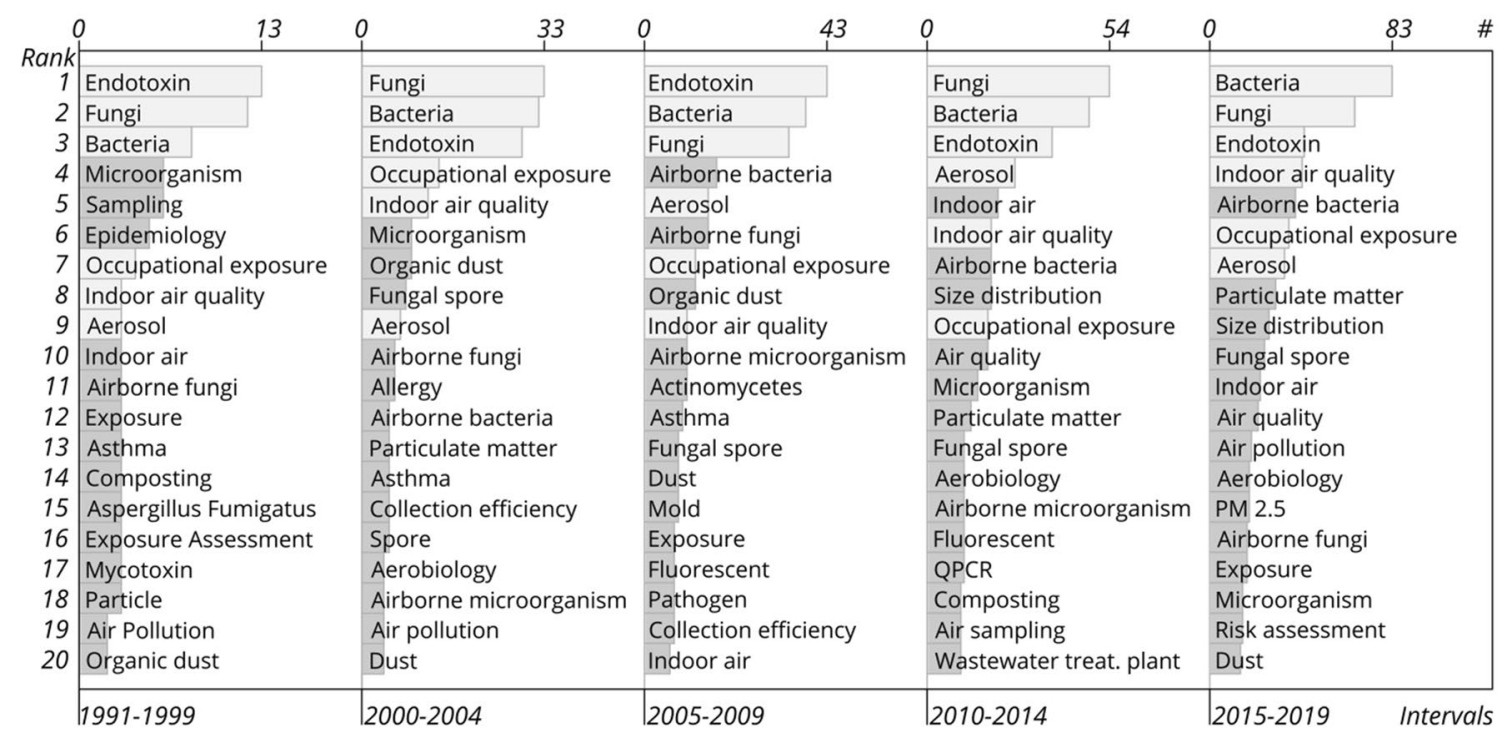

Fig. 9 The evolution of the most used author keywords during 1991-2019 (Light grey keywords occur in every time interval, dark grey keywords occur in the related time interval)

Cluster III represents $21.56 \%$ of the total distribution. "Indoor Air" $(D=58)$ along with "Particulate Matter" $(D=57)$ in Cluster III has a strong connection to the keywords "Fungal Spore", "Air Quality", "PM 2.5", "PM 10", and "Pollen". Fungal spores and pollens contribute to particulate matter and in recent years detection of bioaerosols as a part of particulate matter becomes a current issue (Hyde and Mahalov 2020). Thus, Cluster III, identically with the literature, suggests that particulate matter is one of the hot topics in the bioaerosol research area. Cluster IV corresponds to $12.81 \%$ of the keywords network. "Indoor Air Quality" $(D=80)$ is the central node and "Airborne Bacteria", "Aeromicrobiology", "Indoor Environment", "Monitoring" are common related keywords. Indoor air quality is an important issue in occupational and public health, thus monitoring of airborne microorganisms in indoor air received attention (Mandal and Brandl 2011). The co-occurrence of keywords in Cluster IV indicates that indoor air is a concerned topic 


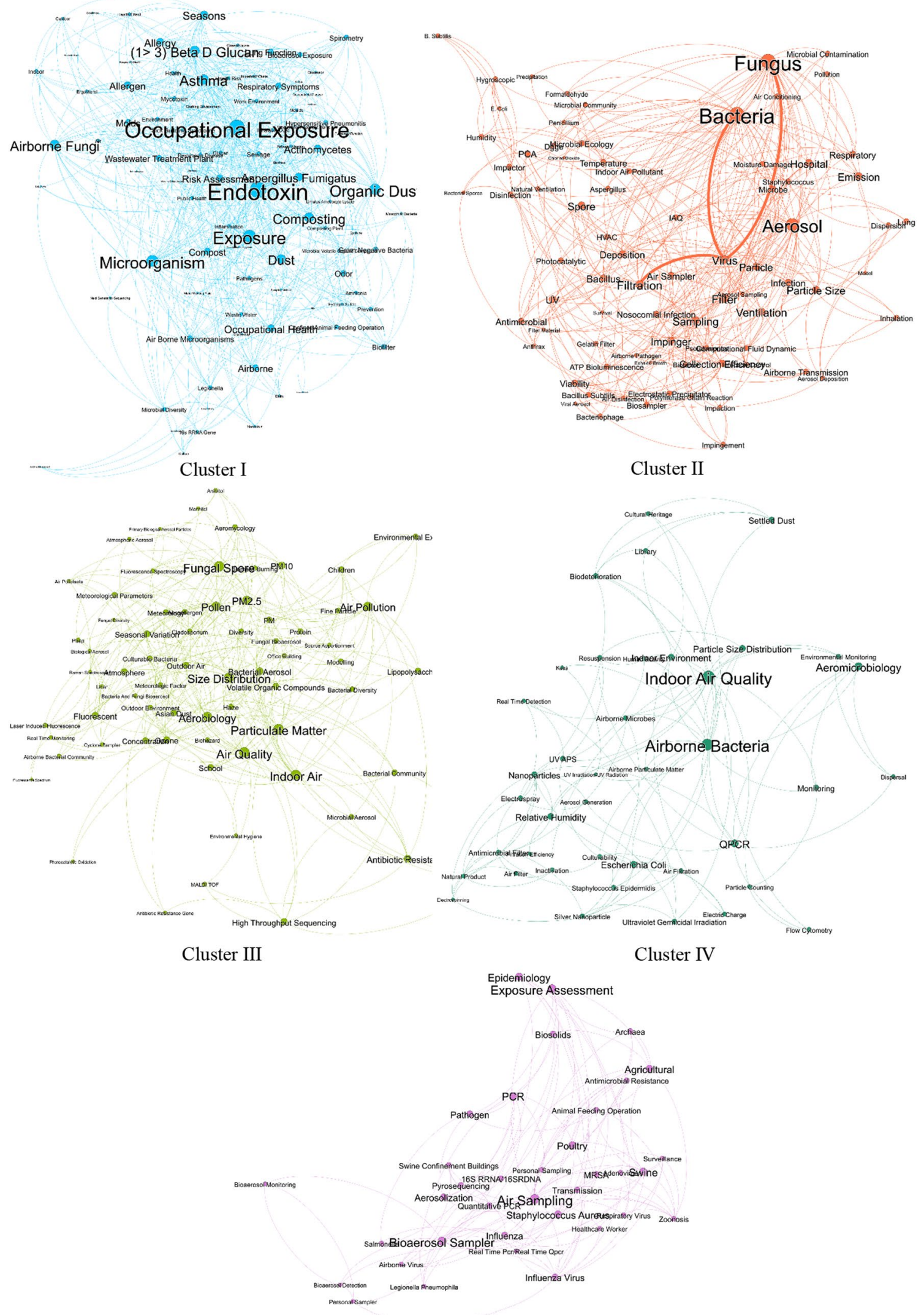

Cluster V

Fig. 10 Clusters in the author keywords network 
in the bioaerosol field. The central node of Cluster V is "Air Sampling" $(D=45)$ and has a close relation to "Exposure Assessment" and "Bioaerosol Sampler". The rest of the keywords in the cluster suggest that this cluster is related to bioaerosol sampling and monitoring likewise Cluster II. An overall evaluation of keywords network analysis revealed that "health-related issues", "occupational exposure to bioaerosols", "sampling and monitoring of bioaerosols", "bioaerosols in the particulate matter", and "indoor air quality" are the main hotspots of bioaerosol research.

\section{Future research needs}

The research trends and hot topics in bioaerosol research were analyzed and presented via keywords and social network analysis in this study. Though many studies on bioaerosols have been carried out on this particular topic, some knowledge gaps and issues are still present. In light of the obtained results in this study, future needs for bioaerosol studies can be summarized as follows:

- Although the history of bioaerosols dates back centuries, the number and variety of studies are still lower and limited in certain countries compared to many other areas. More studies are needed especially covering developing and underdeveloped countries.

- Bioaerosol research is challenging and needs multidisciplinary work involving many disciplines such as aerosol and atmospheric science, microbiology, chemistry, public health, infectious diseases, agriculture, etc. Thus, multidisciplinary studies should be emphasized.

- Considering research hot topics based on keyword analysis, the need for studies related to the role of bioaerosols in climate and atmospheric processes, the behavior of distribution, modeling, and outdoor environment could be deduced.

- In the context of the COVID-19 pandemic, more studies are needed to determine the effect of bioaerosols in the spreading or transmission of infections.

\section{Conclusion}

This study provides an overview of studies associated with bioaerosols, based on 2826 publications extracted from the Web of Science database from 1989 to 2019 and concludes:

- The occasional yearly increases over the past 31 years typically coincided or lagged slightly behind the public health problems with the outbreaks of SARS, MERS, and H1N1 or bioterrorism events like anthrax since airborne transmission is an important pathway of spreading these diseases.
- The most productive and collaborative countries in terms of the total number of publications were the most industrialized or developed countries. The USA is the leading country based on the number of publications and China demonstrated a great interest in bioaerosol research recently and ranked the top in 2019. The worldwide prevalence of collaborative countries reveals that air-related issues are transboundary. Furthermore, collaboration analysis showed that sharing the same geography is likely to result in collaborative studies in a specific area.

- The 2826 papers analyzed in this study were published in 627 different journals indicating the broadness of the area. The most preferred journal is the "Journal of Aerosol Science" while popular research areas and WoS categories pointed out that bioaerosol is a hot topic among environmental scientists.

- The yearly distribution of keywords indicates that studies about components and fragments of bioaerosols along with occupational exposure and indoor air quality were present in the past 30 years. In the last ten years, studies related to "particulate matter" have increased.

- The main hot topics in bioaerosol research are the health effects of bioaerosols especially occupational exposure, bioaerosol sampling, particulate matter relation to bioaerosols, and indoor air quality.

Acknowledgements The author is thankful to Fatih Güven (Ph.D.) with Hacettepe University, Turkey for his work in the preparation of the standardized data extraction algorithm.

\section{Declarations}

Conflict of interest The author declares that she has no conflict of interest.

\section{References}

Aghaei Chadegani A, Salehi H, Yunus M et al (2013) A comparison between two main academic literature collections: web of science and scopus databases. Asian Soc Sci 9:18-26. https://doi.org/10. 5539/ass.v9n5p18

Ariya PA, Sun J, Eltouny NA et al (2009) Physical and chemical characterization of bioaerosols-implications for nucleation processes. Int Rev Phys Chem 28:1-32. https://doi.org/10.1080/ 01442350802597438

Asadi S, Bouvier N, Wexler AS, Ristenpart WD (2020) The coronavirus pandemic and aerosols: does COVID-19 transmit via expiratory particles? Aerosol Sci Technol 54:1-4. https://doi.org/10. 1080/02786826.2020.1749229

Bastian M, Heymann S, Jacomy M (2009) Gephi: an open source software for exploring and manipulating networks. In: Third international AAAI conference on weblogs and social media

Beaumont F (1988) Clinical manifestations of pulmonary Aspergillus infections. Mycoses 31:15 
Can-Güven E, Gedik K (2016) Global research activities on dioxins and dioxin-like compounds. Int J Environ Pollut. https://doi.org/ 10.1504/IJEP.2016.082116

Chen Q, Hildemann LM (2009) The effects of human activities on exposure to particulate matter and bioaerosols in residential homes. Environ Sci Technol 43:4641-4646. https://doi.org/10. 1021/es802296j

Colares GS, Dell'Osbel N, Wiesel PG et al (2020) Floating treatment wetlands: a review and bibliometric analysis. Sci Total Environ 714:136776. https://doi.org/10.1016/j.scitotenv.2020.136776

Cox CS, Wathes CM (1995) Bioaerosols handbook. CRC Press, Boca Raton

Douwes J, Thorne P, Pearce N, Heederik D (2003) Bioaerosol health effects and exposure assessment: progress and prospects. Ann Occup Hyg 47:187-200. https://doi.org/10.1093/annhyg/meg032

Fu H, Ho Y, Sui Y, Li Z (2010) A bibliometric analysis of solid waste research during the period 1993-2008. Waste Manag 30:2410 2417. https://doi.org/10.1016/j.wasman.2010.06.008

Garfield E (1990) Keywords plus-ISI's breakthrough retrieval method. 1. Expanding your searching power on current-contents on diskette. Curr Contents 32:5-9

Güven F, Demirkale B (2018) Determination of global research activities in mechanical engineering via bibliometric analysis. Arch Mech Eng 65:171-188. https://doi.org/10.24425/119414

Humbal C, Gautam S, Trivedi U (2018) A review on recent progress in observations, and health effects of bioaerosols. Environ Int 118:189-193. https://doi.org/10.1016/j.envint.2018.05.053

Hyde P, Mahalov A (2020) Contribution of bioaerosols to airborne particulate matter. J Air Waste Manag Assoc 70:71-77. https:// doi.org/10.1080/10962247.2019.1629360

Jones AM, Harrison RM (2004) The effects of meteorological factors on atmospheric bioaerosol concentrations-a review. Sci Total Environ 326:151-180. https://doi.org/10.1016/j.scitotenv.2003. 11.021

Lee BU (2011) Life comes from the air: a short review on bioaerosol control. Aerosol Air Qual Res 11:921-927. https://doi.org/10. 4209/aaqr.2011.06.0081

Li J, Zhang Y, Veber M et al (2013) Bibliometric analysis of research on secondary organic aerosols: a science citation index expandedbased analysis (IUPAC technical report). Pure Appl Chem 85:1241-1255. https://doi.org/10.1351/PAC-REP-12-08-09

Li C, Wu K, Wu J (2017a) A bibliometric analysis of research on haze during 2000-2016. Environ Sci Pollut Res 24:24733-24742. https://doi.org/10.1007/s11356-017-0440-1

Li Y, Li J, Xie S (2017b) Bibliometric analysis: global research trends in biogenic volatile organic compounds during 19912014. Environ Earth Sci 76:1-13. https://doi.org/10.1007/ s12665-016-6328-4

Li Y, Wang Y, Rui X et al (2017c) Sources of atmospheric pollution: a bibliometric analysis. Scientometrics 112:1025-1045. https://doi. org/10.1007/s11192-017-2421-Z

Li H, Jiang HD, Yang B, Liao H (2019) An analysis of research hotspots and modeling techniques on carbon capture and storage. Sci Total Environ 687:687-701. https://doi.org/10.1016/j.scitotenv. 2019.06.013

Mandal J, Brandl H (2011) Bioaerosols in indoor environment-a review with special reference to residential and occupational locations. Open Environ Biol Monit J 4:83-96. https://doi.org/ $10.2174 / 1875040001104010083$

Morris CE, Sands DC, Bardin M et al (2008) Microbiology and atmospheric processes: an upcoming era of research on bio-meteorology. Biogeosciences Discuss 5:191-212. https://doi.org/10.5194/ bgd-5-191-2008

Pillai SD, Ricke SC (2002) Bioaerosols from municipal and animal wastes: background and contemporary issues. Can J Microbiol 48:681-696. https://doi.org/10.1139/w02-070

Pope CA, Dockery DW, Schwartz J (1995) Review of epidemiological evidence of health effects of particulate air pollution. Inhal Toxicol 7:1-18. https://doi.org/10.3109/08958379509014267

Pritchard A (1969) Statistical bibliography or bibliometrics. J Doc 25:348-349

Ren P, Jankun TM, Leaderer BP (1999) Comparisons of seasonal fungal prevalence in indoor and outdoor air and in house dusts of dwellings in one Northeast American county 1. J Expo Sci Environ Epidemiol 9:560-568. https://doi.org/10.1038/sj.jea.7500061

Rolph CA, Gwyther CL, Tyrrel SF et al (2018) Sources of airborne endotoxins in ambient air and exposure of nearby communities-a review. Atmosphere (basel). https://doi.org/10.3390/atmos91003 75

Šantl-Temkiv T, Sikoparija B, Maki T et al (2019) Bioaerosol field measurements: challenges and perspectives in outdoor studies. Aerosol Sci Technol. https://doi.org/10.1080/02786826.2019. 1676395

Schlosser O (2019) Bioaerosols and health: current knowledge and gaps in the field of waste management. Detritus. https://doi.org/ 10.31025/2611-4135/2019.13786

Siersted HC, Gravesen S (1993) Extrinsic allergic alveolitis after exposure to the yeast Rhodotorula rubra. Allergy 48:298-299. https:// doi.org/10.1111/j.1398-9995.1993.tb00734.x

Stetzenbach LD (2007) Introduction to aerobiology. In: Manual of environmental microbiology, 3rd edn. American Society of Microbiology, pp 925-938

Taddeo R, Simboli A, Di Vincenzo F, Ioppolo G (2019) A bibliometric and network analysis of Lean and Clean(er) production research (1990/2017). Sci Total Environ 653:765-775. https://doi.org/10. 1016/j.scitotenv.2018.10.412

Xie S, Zhang J, Ho YS (2008) Assessment of world aerosol research trends by bibliometric analysis. Scientometrics 77:113-130. https://doi.org/10.1007/s11192-007-1928-0

Xu Z, Wu Y, Shen F et al (2011) Bioaerosol science, technology, and engineering: past, present, and future. Aerosol Sci Technol 45:1337-1349. https://doi.org/10.1080/02786826.2011.593591

Yang LY, Yue T, Ding JL, Han T (2012) A comparison of disciplinary structure in science between the G7 and the BRIC countries by bibliometric methods. Scientometrics 93:497-516. https://doi.org/ 10.1007/s11192-012-0695-8

Zhang J, Wang MH, Ho YS (2012) Bibliometric analysis of aerosol research in meteorology and atmospheric sciences. Int J Environ Pollut 49:16-35. https://doi.org/10.1504/IJEP.2012.049733

Zhao S, Hou H, Jiao L, Yang T (2016) A bibliometric analysis for global PM2.5 research. Fresenius Environ Bull 25:5080-5095 